\title{
Low-Cost Strategies to Improve Municipal Solid Waste Management in Developing Countries: Experimental Evidence from Nepal
}

\author{
Mani Nepal ${ }^{1} \mathbb{D} \cdot$ Apsara Karki Nepal $^{2} \cdot$ Madan S. Khadayat $^{3} \cdot$ Rajesh K. Rai $^{4}$. \\ Priya Shyamsundar $^{5}$ E. Somanathan ${ }^{6}$
}

Accepted: 25 November 2021 / Published online: 1 January 2022

(C) The Author(s) 2021

\begin{abstract}
Many cities in developing countries lack adequate drainage and waste management infrastructure. Consequently, city residents face economic and health impacts from flooding and waterlogging, which are aggravated by solid waste infiltrating and blocking drains. City governments have recourse to two strategies to address these problems: a) 'hard' infrastructure-related interventions through investment in the expansion of drainage and waste transportation networks; and/or, b) 'soft', low-cost behavioural interventions that encourage city residents to change waste disposal practices. This research examines whether behavioural interventions, such as information and awareness raising alongside provision of inexpensive street waste bins, can improve waste management in the city. We undertook a cluster randomized controlled trial study in Bharatpur, Nepal, where one group of households was treated with a soft, low-cost intervention (information and street waste bins) while the control group of households did not receive the intervention. We econometrically compared baseline indicators - perceived neighbourhood cleanliness, household waste disposal methods, and at-source waste segregation - from a pre-intervention survey with data from two rounds of post-intervention surveys. Results from analysing household panel data indicate that the intervention increased neighbourhood cleanliness and motivated the treated households to dispose their waste properly through waste collectors. The intervention, however, did not increase household waste segregation at source, which is possibly because of municipal waste collectors mixing segregated and non-segregated waste during collection. At-source segregation, a pre-requisite for efficiently managing municipal solid waste, may improve if municipalities arrange to collect and manage degradable and nondegradable waste separately.
\end{abstract}

Keywords At-source segregation - Low-cost intervention - Municipal solid waste $\cdot$ RCT . Low-cost waste bins $\cdot$ Nepal

Mani Nepal

Mani.Nepal@icimod.org; mani.nepal@bus.illinois.edu

Extended author information available on the last page of the article 


\section{Introduction ${ }^{1}$}

Unplanned urbanization is one of the key challenges that developing countries are facing (Cohen 2006; UN-Habitat 2004). Many cities in low- and middle-income countries (LMICs) lack adequate basic infrastructure such as roads, sanitation and drainage networks and face a multitude of problems related to traffic congestion, air pollution, high crime rate and waste mismanagement (Nam and Pardo 2011). Rapid population growth, increased economic activities, and climate change make urban management even more complex, with frequent extreme weather conditions such as short-duration high-intensity rainfall events leading to waterlogging and flooding. Smart cities is an emergent new concept in LMICs that takes into consideration these developments and attempts to make cities more liveable (Alawadhi et al. 2012) by utilizing information and communication technologies and addressing infrastructure needs (Nam and Pardo 2011; Visvizi et al. 2018).

Municipal solid waste (MSW) management is vital to making cities clean, liveable and smart (Medvedev et al. 2015; Esmaeilian et al. 2018; Rai et al. 2019). Residents place a high premium on housing property when solid waste is managed well in the neighbourhood (Nepal et al. 2020). When MSW is not well managed, drainage systems get clogged, especially with waste-packed plastic bags, contributing to waterlogging and urban flooding (Tawhid 2004; Pervin et al. 2020). Existing infrastructure for waste disposal, collection services and management facilities in developing countries are often inadequate (Henry et al. 2006; Guerrero et al. 2013). However, the solution does not lie in financial and infrastructure improvements alone. Knowledge, practices and attitudes of urban residents are also key to better municipal solid waste management (Barr 2007; Desa et al. 2011).

Both hard and soft interventions can contribute to good MSW management. But investments in hard infrastructure such as sewage and drainage systems are expensive undertakings for municipal authorities in developing countries (Huang et al. 2011; Guerrero et al. 2013). In such contexts, low-cost strategic and behavioural interventions can usefully enhance the efficacy of existing infrastructure. Empirical studies show that household preferences regarding the frequency and timing of waste collection and access to street waste bins influence how municipal waste is disposed (Almazán-Casali et al. 2019; Rai et al. 2019). In addition, public awareness on the importance of proper waste disposal contributes to demand for cleaner cities, which is essential for improving MSW management (Hasan 2004; Joseph 2006). Banning single-use plastic bags, which is a major contributor to drain clogging and non-biodegradable MSW, has been proposed as one alternative to reducing plastic litter in the cities. But it must be carefully designed with sufficient monitoring, enforcement, and significant fines against those who violate the ban for it to be effective (Bharadwaj et al. 2020a, b).

Against this backdrop, our study examines the following question: What would be the effect of low-cost soft interventions for the improvement of municipal solid waste management in a developing country? To answer this question, we implement a randomized controlled trial (RCT) in Bharatpur, Nepal. RCT is one of the widely used methods in impact

\footnotetext{
1 The authors have been associated with the South Asian Network for Development and Environmental Economics (SANDEE) in various capacities, and they would like to dedicate this article to Professor Karl-Goran Maler, who was one of the founders of SANDEE. For additional information on Professor Maler's contribution to the establishment and growth of SANDEE as a research capacity and leadership development network in South Asia, please see http://www.sandeeonline.org/uploads/documents/publication/ 892_PUB_A_Decade_in_Focus.pdf (accessed on November 21st, 2021).
} 
evaluation research, with randomization helping to identify causal relationships between interventions and outcomes (Khandker et al. 2009). In the context of MSW management, RCTs have been used to shed light on numerous issues, including the effect of inducements or messaging on waste segregation (Hosono and Aoyagi 2018; Abbasi et al. 2020), the influence of recycling campaigns (Cotterill et al. 2009), and the impact of feedback on waste generation (Nomura et al. 2011). These studies provide policy-relevant information, clarifying what works and what does not with waste separation and organisation. Many of the studies, however, have been conducted in developed countries, with relatively few undertaken in low- and middle-income countries. Thus, our study adds to the literature on the use of RCTs to address MSW management challenges in developing countries. Assessing the effectiveness of low-cost and soft MSW interventions is particularly important as solid waste is projected to grow with urbanization and changing consumer habits in LMICs (Hoornweg and Bhada-Tata 2012).

In our experiment, randomly assigned treatment communities received low-cost street waste bins, with residents and community leaders receiving information on how to better manage household waste by segregating it at source and disposing it properly, replacing current practices such as open-space dumping or burning. We conducted three rounds of a survey (a baseline survey and two post-intervention surveys) in 75 control and 75 intervention communities to obtain data from 1050 households. The two rounds of the post-intervention survey sought to address the problem of "low power" in RCT experiments and to assess whether the effects of the outcomes persisted over time (Levitt and List 2011). Our results suggest that the two low-cost interventions improved waste disposal strategies. The proportion of households providing their waste to the collectors increased (from 7.6 to 11.4 percentage points) and there were significant improvements in perceived neighbourhood cleanliness (from 12.4 to 21.1 percentage points).

The findings, however, indicate that information provision did not increase segregation of household waste into perishable and non-perishable waste. One possible explanation is that households did not see any benefit in at-source segregation as the city did not collect perishable and non-perishable waste separately. However, at-source segregation is an important aspect of solid waste management. It enables paper, plastic and metal recycling, which can help cover a portion of the municipal waste management costs (Bharadwaj et al. 2020b). Segregated organic waste, on the other hand, can be composted and used as fertilizer, thereby reducing waste volume in landfills and decreasing collection and transportation costs. Additionally, the separation of perishable waste for composting and recyclable items can help increase the life of landfill sites. Our study, therefore, points to potential complementarities between soft interventions such as information provision and more costly system-wide actions, with both being required for significant gains in MSW management.

\section{The Context}

\subsection{National Scenario}

After the promulgation of the new Constitution in 2015, all human settlements in Nepal are administered through two forms of local government-293 urban municipalities and 460 rural municipalities. In all, 753 local governments govern Nepal's population of approximately 30 million. In the current structure, urban municipalities cover metropolitan cities 


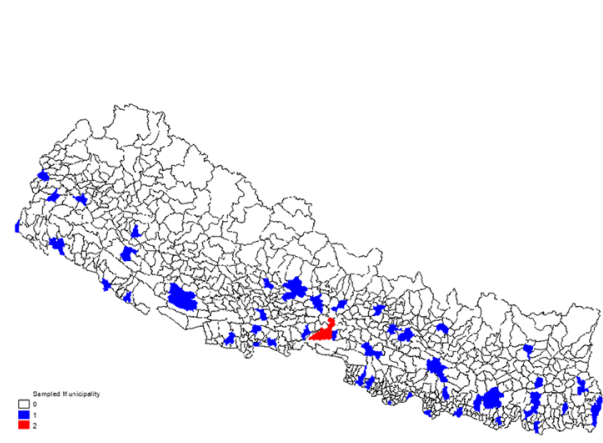

(a) Map of Nepal with 58 Municipalities

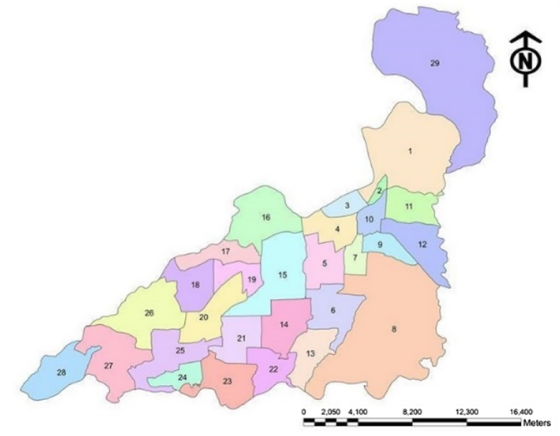

(b) Bharatpur Metropolitan City

Fig. 1 Study site. Notes: In panel (a), the red color indicates Bharatpur Metropolitan City and the blue color indicate other municipalities across the country (based on the 2011 Census). Panel (b) shows wards (the smaller administrative units) within the Bharatpur Metro. For the purposes of this study, we included the core-city area of Bharatpur and its surroundings comprising 14 wards (1-14). Sources: (a) Nepal et al. (2020), (b) Rai et al. (2019)

(six), sub-metropolitan cities (11) and municipalities (276). These municipalities are further divided into administrative units called wards for managing local needs. The country's urban population ( $17 \%$ in 2011 in 58 municipalities $^{2}$ (Fig. 1)) is expected to increase to more than $50 \%$ of Nepal's population in the next census count ${ }^{3}$ because of reclassification of cities.

It is likely that population growth in urban municipalities has exerted pressure on urban infrastructure, including municipal waste management. The Local Government Operation Act 2018 assigns the responsibility for waste management and sanitation-related service provision to local governments (GoN 2018). Key responsibilities include awareness raising on sanitation and waste management, collection and disposal of waste, resource mobilization, and forging partnerships with the private sector.

A recent survey conducted by the Nepal Central Bureau of Statistics (CBS 2021) indicates that, on average, urban municipalities spend $1.43 \%$ (NPR 10 million or USD $90 \mathrm{~K}$ ) of their annual budget to address environment-related issues, including waste management. Only $30 \%$ of the municipalities generate resources locally (on average NPR 1.34 million or USD $12 \mathrm{~K}$ per municipality) by imposing waste management tariffs on service seekers (NPR 30-100 per month per household and entity (institutions and businesses combined)). Thus, $70 \%$ of municipalities fully rely on the central government for budgetary allocations for managing municipal solid waste, highlighting the lack of capacity among the newly formed municipalities to mobilize local resources. Given limited resources, on average, less than $50 \%$ of the waste generated within the municipalities is collected even among those municipalities that collect solid waste. The survey, moreover, indicates that, on average, metropolitan cities in Nepal generate 24,000 MT of waste per year, with only

\footnotetext{
2 https://cbs.gov.np/national-population-and-housing-census-2011-major-highlights/ (accessed on May 27, 2021).

3 The next population census is concluded in December 2021 but it would take time to obtain the actual share of urban population from it. The difference between rural and urban municipalities in terms of physical infrastructure has been blurred in Nepal after the new classification of human settlements.
} 
$33 \%$ of the city streets and public places cleaned. The uncollected waste is either dumped in any available land area (open dumping) or burnt by residents. In the survey, $21 \%$ of the municipalities reported open dumping, 32\% reported open burning, and $27 \%$ reported piling it up by the riverside.

The CBS survey (CBS 2021) also collected information on the challenges faced by municipalities in managing solid waste. The top five challenges reported were overall waste management (60\%), lack of awareness among residents $(50 \%)$, lack of resources $(48 \%)$, lack of landfill sites (45\%), and lack of human resources (22\%). Among the immediate needs identified by municipalities were trained human resources $(50 \%)$, provision of landfill sites (50\%), allocation of an adequate budget (43\%), provision of machines and other instruments (42\%) and awareness raising (34\%).

\subsection{Study Area}

The study was conducted in Bharatpur (Fig. 1), the fifth largest city in Nepal. With a population of over 300,000 , and spread over $433 \mathrm{~km}^{2}$, it is one of the fastest growing cities in the country with an annual population growth of $6 \%$ in the past decade. ${ }^{4}$ The city is located in the south-central part of the country surrounded by productive agriculture fields. In 2012, the estimated waste generation in Bharatpur, with just 14 wards, was around 40 tons per day, $25 \%$ of which was collected through formal channels (Asian Development Bank 2013). Today, the city has 29 wards, with more waste generated per day.

The city has been collecting and managing municipal solid waste using a public-private partnership model, where private contractors collect and dispose of household waste. They provide door-to-door collection services, particularly in the core city area. Participating households pay for their services through a monthly tariff, established by the Tole Lane Organization (TLO), based on the frequency of collection. An average TLO comprises around 100 households (the number ranging from 23 to 210) at the neighbourhood level in the city. It is a community-based organization registered with the municipal authority to coordinate community-level development and sanitation activities among others. By 2017, Bharatpur had about 600 registered TLOs.

The city encourages households to reduce and better manage their waste. It supports waste segregation at home by providing a 50 percent subsidy to households on a composter that households can use to produce compost fertilizer. However, due to supply constraints (budgetary limitations), not all households who wish to use composters can get one. In addition, plastic recyclers have distributed suiro (iron hooks) to gather plastic, with the expectation of collecting 37 ton of plastic waste per month (SWMRMC 2004). However, we were not able to gather verifiable information on the success of the suiro program in reducing plastic litter in the city.

In Bharatpur, 94\% of municipal households in the core area of the city subscribe to municipal solid waste collection services (Rai et al. 2019). While over $90 \%$ has a door-todoor collection system, some households use common collection points because of lack of road access. However, over $50 \%$ of households are not satisfied with the existing municipal waste collection services as streets are unclean despite the levying of a monthly fee for waste management. Dissatisfaction stems from the lack of synchronization between the time when waste bins/bags are placed outside their houses by the residents and waste pick

\footnotetext{
${ }^{4}$ https://bharatpurmun.gov.np/en/node/27 (accessed on November 17, 2020).
} 
up time. In a linked study, households indicate a clear preference for two alterations in the existing system: a) a pre-determined and convenient waste collection time; and b) installation of waste bins in the street (Rai et al. 2019). Nepal et al. (2020) have shown that Bharatpur residents place a high premium on residential housing units that are located in neighbourhoods which are perceived to be clean.

The current situation of waste management in Bharatpur, in addition to being a cause of disease and discomfort, has implications for long-term flood risk management. About $13 \%$ of the land area in Bharatpur is currently under flood risk (Pervin et al. 2020). This area can be reduced to 5\% with structural interventions in the drainage system. Even with such investments, the flood risk can increase to $8 \%$ in five years in the absence of proper solid waste management, reducing thereby the returns from the investment within a short period of time (Nepal et al. 2022a). Thus, structural solutions alone are almost ineffective in reducing long-term flooding and waterlogging risks in the city. Behavioural changes among city residents are essential for better management of Bharatpur's municipal solid waste.

\section{Methodology}

\subsection{Theory and Practice}

Barr et al. (2001) and Barr (2007) have used a conceptual framework for understanding the three major principles of solid waste management, namely, reduce, reuse and recycle (commonly referred to as the $3 \mathrm{Rs}$ ). The framework identifies three elements that are at the core of the 3Rs principle-environmental values, psychological factors (individual perception of both motivators and barriers), and situational characteristics (enablers or disablers such as socio-demographics, context, and experience)—which determine both intention as well as behaviour related to waste management. According to Barr (2007), recycling behaviour is normative (accepted behaviour) as opposed to reduction and reuse, which depend on environmental values and knowledge about the environment. While recycling tends to increase with facilities such as easily accessed recycling bins, it may simultaneously discourage reduce and reuse behaviour. Awareness-raising campaigns can strengthen proenvironmental values, increase knowledge of environmental policies, and make people act responsibly in managing waste (Barr et al. 2001; Barr 2007). As Tucker and Speirs (2003) have pointed out, households with a positive predisposition or attitude towards waste composting may require the right set of triggers to engage in waste management. Information campaigns constitute one such trigger.

The literature on experimental studies in developing country contexts on what works and what does not work with regard to better management of municipal waste is thin. Some studies have focused on information campaigns but, as far as we can assess, there has been no experimental evidence related to low-cost street waste bin provision. Kalyanasundaram et al. (2021), for instance, conducted a cluster-randomized experimental study in Madhya Pradesh, India, where local volunteers were used for an information campaign to promote waste segregation at source. However, the results of this study are yet to be published. Hosono and Aoyagi (2018) reported on a study in Mozambique where a campaign for information dissemination and provision of waste bins for waste segregation that targeted 
households increased at-source segregation and recycling although the interventions were less cost effective compared to other recycling projects.

In the South Asian context, waste collection is generally partial and inefficient, with limited at-source segregation. When waste is collected mixing perishable and recyclable waste together indiscriminately, the collection cost goes up due to the high volume while the life of the landfill declines and recycle rates too go down as mixed waste yields lower rates of material recovery. In India, for example, $95 \%$ of the total budget for waste management goes for collection and transportation, leaving only $5 \%$ for safe disposal. This is the opposite of what happens in developed countries where better waste management systems are in place (Priti and Mandal 2019). In developing countries, investment in waste infrastructure does not keep pace with waste generation. Moreover, relatively few innovative or behavioural strategies are being used to trigger the 3Rs of waste management in developing countries.

\subsection{Theory of Change}

The theory of change behind the experiment to improve municipal solid waste management is based on lessons from the literature and a series of expert and focus group interviews in Bharatpur, Nepal. In several focus group discussions, participants indicated their lack of satisfaction with existing municipal solid waste management services. Households, however, were not very clear on how to improve the different aspects of household waste management. Nevertheless, they indicated that, in the absence of waste bins on the streets, people litter the streets and dump waste in drains while households do not give their waste to the waste collector due to lack of awareness. Therefore, we surmised that better information and an increase in waste bins on the streets could increase at-source segregation and encourage households to handover their waste to waste collectors. This would, in turn, reduce the waste disposed in open spaces and drains. Waste bins on the street would also encourage visitors to place their litter in the bins instead of dropping it on the street contributing that way to cleaner neighbourhoods.

Thus, our theory of change identifies an intervention with two components: (a) provision of in-depth information to households and TLO executive committee members through workshops, pamphlets and posters on the basic principles of household waste management (see Figs 7 and 8 and in the Appendix for examples of such posters); and (b) installation of waste bins on the streets. Since the two components were combined and implemented in the treatment communities as a part of the same intervention package, we estimate the combined effect of both components. Figure 2 illustrates the theory of change, identifying the key interventions, outputs and outcomes as well as the intended impacts because of the interventions.

The study organized information campaigns on waste management through sensitization workshops and installed low-cost street waste bins in 75 randomly selected treatment communities. Immediate outputs from the intervention included 75 TLO executive committee members and around 1800 residents (including members from the sampled households) trained on issues such as the basic principles of waste management (3Rs), segregation methods and impacts of inappropriate waste disposal. The expected outcomes are increased awareness and knowledge among residents and TLO members about the basic principles of solid waste management and city visitors and street users placing their waste (e.g., plastic covers and containers of food items and fruits peel) in easy to access waste bins. The three 


\begin{tabular}{|c|c|c|c|}
\hline Interventions & Outputs & Outcomes & Impacts \\
\hline $\begin{array}{l}\text { Information } \\
\text { Campaign: } \\
\text { Awareness } \\
\text { workshops for } \\
\text { residents and } \\
\text { TLO Executive } \\
\text { Committee } \\
\text { members. } \\
\text { Low-cost } \\
\text { infrastructure } \\
\text { provision: } \\
\text { Installation of } 20 \\
\text { litre waste bins } \\
\text { on streets }\end{array}$ & $\begin{array}{l}\text { a. } 75 \text { TLOs } \\
\text { executive } \\
\text { committee } \\
\text { members \& } 1800 \\
\text { residents were } \\
\text { trained in basic } \\
\text { principles of } \\
\text { MSW. } \\
\text { b. } 1500 \text { waste } \\
\text { bins were } \\
\text { installed in } \\
\text { intervention } \\
\text { TLOs' streets. }\end{array}$ & $\begin{array}{l}\text { a. Residents and TLO } \\
\text { executive committee } \\
\text { members are aware of } \\
\text { the basic principles of } \\
\text { solid waste } \\
\text { management. } \\
\text { b. City visitors place } \\
\text { their food and other } \\
\text { waste in street bins. }\end{array}$ & $\begin{array}{l}\text { a. Improvement in } \\
\text { waste segregation at } \\
\text { source. } \\
\text { b. Household give } \\
\text { waste to collectors } \\
\text { instead of disposing } \\
\text { it outside home or } \\
\text { burning. } \\
\text { c. Neighbourhoods } \\
\text { and streets are } \\
\text { cleaner in the } \\
\text { intervention TLOs. }\end{array}$ \\
\hline
\end{tabular}

Fig. 2 Theory of change. Source: Authors

outcomes expected as a result of the intervention are: (a) an increase in at-source segregation of degradable and non-degradable household waste; (b) increase in households waste given to waste collectors (instead of disposal in open spaces or burning); and (c) cleaner streets as a result of visitors placing their litter in the street waste bins provided.

\subsection{Study Design, Survey and Intervention}

\subsubsection{Study Design}

The study adopts a cluster randomized controlled trial (RCT) design to evaluate the impacts of the information campaign and the installation of low-cost street waste bins on street cleanliness, improved waste disposal and segregation of household waste at source. The choice of the treatment (information campaign and installation of $20 \mathrm{~L}$ waste bins on the street) was based on several focus group discussions with local stakeholders. Both components of the intervention were implemented in the same communities as a part of the same treatment while the control communities did not receive any treatment.

The sample selection was done in three stages: (i) stratification of the core city area by wards, (ii) random selection of control and treatment TLO clusters from each ward using a lottery, and (iii) systematic random selection of a sample of households in each TLO. In Bharatpur, there are 14 wards (based on the administrative classification at the time of the study) in the core city area and its periphery. Each ward is made up of multiple TLOs based on the population in the ward, with a total of approximately 350 TLOs across the 14 wards. We first stratified the study area by wards. We then randomly selected 75 TLOs (Group A) using the PPS sampling technique and another 75 TLOs (Group B), thereafter, using the same sampling technique from the 14 wards. ${ }^{5}$ In selecting Group B, we avoided the TLOs

\footnotetext{
5 The number of TLOs sampled from each ward was based on how many TLOs there were in total in each ward. We selected more TLOs from wards with a large number of TLOs and fewer TLOs from wards with less TLOs.
} 
Table 1 Balancing test (baseline information)

\begin{tabular}{lccc}
\hline Variables & Control & Intervention & Mean difference \\
\hline Outcomes & & & 0.025 \\
Perceived TLO cleanliness & 0.487 & 0.462 & 0.024 \\
Waste given to collector & 0.874 & 0.850 & 0.008 \\
Waste segregated at home & 0.834 & 0.826 & $0.060^{*}$ \\
TLO characteristics & & & $-0.098^{* * *}$ \\
Waste collection frequency & 0.497 & 0.437 & 0.097 \\
No of TLO meetings per year & 0.721 & 0.820 & -0.032 \\
Household characteristics & & & 0.63 \\
Family size & 5.018 & 4.921 & -0.054 \\
Female respondent & 0.605 & 0.638 & 42.547 \\
Age of respondent & 43.176 & 8.771 & \\
Education of respondent & 8.717 & & \\
\hline
\end{tabular}

Total sample size $=993$ households $($ control $=499$ and intervention $=494) ; * * p<0.01, * * p<0.05,{ }^{*} p<0.1$

neighbouring those already sampled in Group A to prevent leakage of information from intervention TLOs to control TLOs. After selecting the two sets of TLOs (Groups A and $\mathrm{B})$, we randomly selected one group as the control TLO cluster and the other as the intervention TLO cluster.

The selection of the TLOs was performed in the presence of municipal officials to avoid pressure from the residents to install bins in areas of their choice. However, the identity of the TLO clusters (intervention or control) was not revealed to the enumerators and city officials until the completion of the baseline survey to ensure that baseline information was not influenced by the assignment of treatment or control status to the TLOs. Avoiding neighbouring TLOs in the oppositive cluster (A or B) is expected to reduce the contamination of results due to spill over effect. However, as the wards and TLOs are managed by different officials and committees, randomization may not completely balance the characteristics of the TLOs included in the sample. This may constitute a source of some bias.

\subsubsection{Baseline Survey}

For the household survey, we surveyed 7 households from each control and treatment TLO using systematic random sampling, where in each TLO the first household was selected randomly, and the remaining households were selected systematically maintaining a fixed interval. The interval was determined by dividing the total number of households in each TLO by $7 .^{6}$ The list of households was obtained from the Bharatpur Metropolitan City Office. In total, we planned to undertake a baseline survey of 1050 households from 150 TLOs. The final sample size was slightly lower (discussed below and presented in Table 1) due to some attrition in successive rounds of the survey and missing information.

\footnotetext{
${ }^{6}$ Since the number of households in each TLO are not the same, selection of households is not based on the proportion to the size sampling scheme.
} 


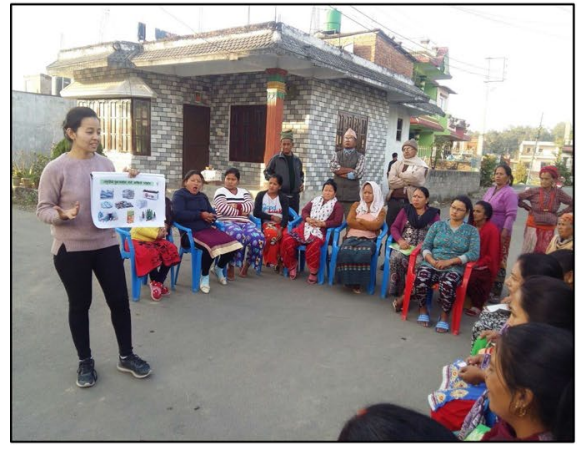

(a) Introducing the 3Rs to the participant

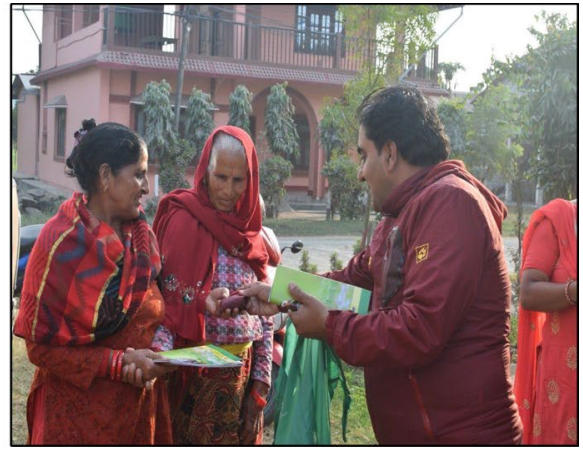

(b) A TLO head distributing pamphlets

Fig. 3 Sensitization workshops. Photo credit: Clean Up Nepal (field partner in the research project)

We surveyed the head of the sampled household of either gender depending on their availability. In case the household head was absent during the first visit, the enumerators revisited the household. Before the second visit, the enumerators contacted the household head to ensure the availability of the head for an interview. All surveyed households were marked with a permanent marker to make identification easy during the next two visits. Their GPS locations were also collected for the same purpose. In addition to households, members of the executive committee of the selected TLO (Chairperson or Secretary who would have better information about the community) were also interviewed to collect community-level information related to solid waste management.

The survey questionnaire collected demographic and socio-economic data in addition to information on outcome variables such as household behaviour relating to waste generation and management and their perceptions on TLO cleanliness. ${ }^{7}$ The survey also collected community-level information such as frequency of waste collection and TLO meetings per year.

After the baseline survey, well-trained field teams from Bharatpur conducted the field intervention described below. Questionnaires were translated into the local language (Nepali) and data collected using electronic devices. The first-round (baseline) survey was conducted in September-October 2017 before the intervention.

\subsubsection{Intervention}

The intervention had two components: (i) information provision through pamphlets, posters and sensitization workshops for executive committee members of the TLOs and households, and (ii) installation of low-cost $20 \mathrm{~L}$ waste bins on the streets for community use.

Information was provided through 75 sensitization workshops in the 75 TLOs selected (intervention group). Fifteen facilitators from the city were trained and divided into five groups of 3 persons each. Each facilitation group was assigned 15 TLOs in which to conduct workshops, with each workshop lasting between 3 and $4 \mathrm{~h}$. The sensitization workshops were organized over a one-week period (December 17-24, 2017). The workshops

\footnotetext{
7 The survey instrument is available from the corresponding author upon request.
} 


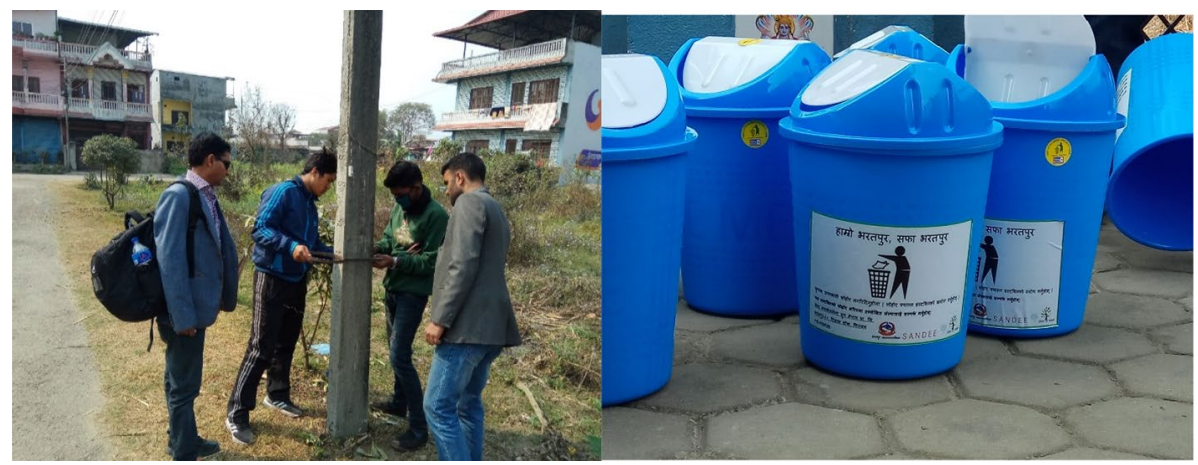

Fig. 4 Waste bin installation on the streets. Photo credit: The study team

emphasized key issues such as current practices of waste management in the city, the importance of waste segregation, the 3 Rs (reduce, reuse, and recycle) principles of waste management, composting, and impacts of waste burning and littering. Power point slides, posters, and live demos were used to convey the different concepts and ideas involved in proper management of household waste. Small pamphlets containing the key messages were provided to the participants for future reference. A total of over 1800 people attended the 75 sensitization workshops, with around 25 people in each workshop. Figure 3 provides a glimpse of the sensitization workshops while the Appendix presents the sample posters used in workshops (Figs. 7 and 8).

In addition to the sensitization workshops, 1500 street waste bins were installed in the intervention TLOs (Fig. 4). Clean Up Nepal (CUNP), a national non-governmental organization working in the waste management sector and a field partner in the study, recruited 5 individuals to strategically assess bin placement. Assessments were based on ease of access, proximity to residential areas, waste hotspots and the TLO population. Clean Up Nepal mobilized volunteers to assess each TLO with the assistance of key stakeholders (TLO representatives and staff from waste companies) so as to create street maps and identify places for installing the waste bins. The bins have stickers with information on the waste company's phone number based on their catchment area. The TLO committees agreed to monitor the bins so that they were protected and utilized for the sole purpose of collecting litter and not for collecting household waste. The waste management companies were informed to empty the waste bins during their service days.

\subsubsection{Outcome Indicators}

In this study, the outcome indicators include (a) waste segregation at source, (b) waste provided to the collectors, and (c) perceived cleanliness of the streets. Self-reported information on these indicators was collected at the household level through three rounds (baseline, midline and endline) of household surveys.

\subsubsection{Follow-up Surveys}

After the completion of the intervention workshops and installation of waste bins on the streets, the survey team revisited the sampled households maintaining a three-month gap 


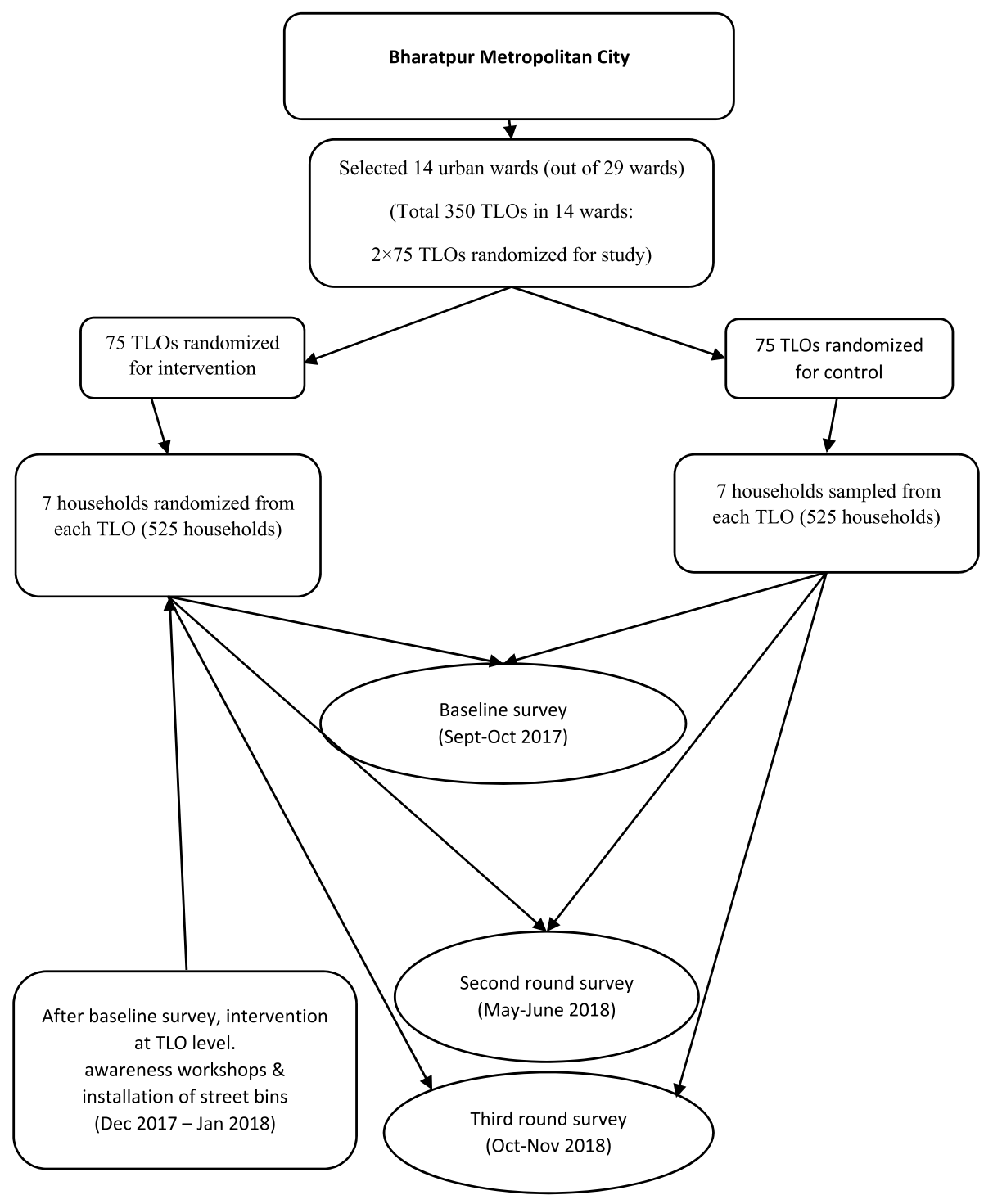

Fig. 5 Study design

between the completion of bin installation and the second visit. The same households were therefore surveyed a second time in May-June 2018 (midline survey) and a third time in October-November 2018 (endline survey). All TLO executives were also surveyed in the three rounds. Figure 5 provides a detailed schematic of the study design.

Out of the 1050 planned households for the survey, only 1043 were surveyed in the baseline. Seven households from a remote TLO from the control group were dropped since the enumerators could not meet the TLO executive committee members when they visited the community. In the first follow-up round (midline survey), 1036 households were 
surveyed with one more TLO dropped due to the same reason. In the final round, 1035 households were surveyed. The attrition rate (1.4\% of the planned households) was, therefore, low in the successive rounds. After dropping a few households because of missing information and balancing the panel for all three rounds, 993 households remained for the analysis (see Table 1). Two post-intervention surveys were conducted at three-month intervals to examine whether the effect of the information disseminated at the workshops remained beyond the first three months.

\subsubsection{Ensuring Data Quality}

For minimizing the likelihood of errors during data collection, a dedicated field supervisor (one of the authors) monitored the field data collection during all three rounds. Since the data were collected using electronic devices, data collection was continuously monitored and errors immediately corrected. Five trained enumerators (a majority of them women) from the local area were used in each round of the survey. Before starting each round of the survey, the research team trained the enumerators extensively at a workshop-type setting for two days and in the field for one day.

\subsection{Empirical Approach}

In this study, we examine the effect of awareness-raising workshops and low-cost street waste bins on three municipal solid waste management-related outcomes at the household level. We use two specifications for analyzing the three-rounds of survey data. Since a RCT design was used, the variables in control and intervention communities, in principle, should be balanced in the baseline. We, therefore, control for any unbalanced baseline variables while estimating the effect of the intervention. Equation (1) gives the basic specification, which uses data from the midline and endline surveys, to compare outcomes associated with intervention and control households:

$$
Y_{h t v w}=\beta_{w}+\beta_{1} \cdot \text { Intervention }_{T L O_{v w}}+\beta_{2} \cdot e_{t}+\beta_{3} \cdot X_{t v w}+\varepsilon_{h t v w}
$$

where, $Y_{h t v w}$ refers to an outcome variable (one among the three binary outcomes: waste segregation, waste given to the collector and cleaner streets) for the $h^{\text {th }}$ household in round $t$ (either midline or endline) in TLO $v$ in ward $w ; \beta_{w}$ is the ward fixed effect, Intervention_TLO $O_{v w}$ is a dummy for a treatment TLO, $e_{t}$ is a dummy for the endline round, $X_{t v w}$ is a vector of the unbalanced baseline characteristics of the communities (frequency of waste collection and number of TLO meetings per year, see Table 1) and the interaction terms between the enumerator's IDs and survey round (to control for enumerator-specific effects on the survey responses). Since the intervention was assigned randomly across the TLOs, the error term $(\varepsilon)$ is assumed to be distributed normally. $\beta_{1}$ is the coefficient that captures the impact of the intervention and $\beta_{2}$ is the coefficient of the endline time dummy.

Since we collected three rounds of survey data, with full baseline information before the intervention and two rounds after the intervention ( $m$ and $e$ ), we use the following alternative (extended difference-in-difference) specification that allows the outcomes and the treatment effects to vary over time. This specification also allows us to control for baseline differences in outcomes between treatment and control groups. While the treatment and control groups are expected to be balanced on average by virtue of randomization, they are not exactly balanced in the sample (Table 1). 


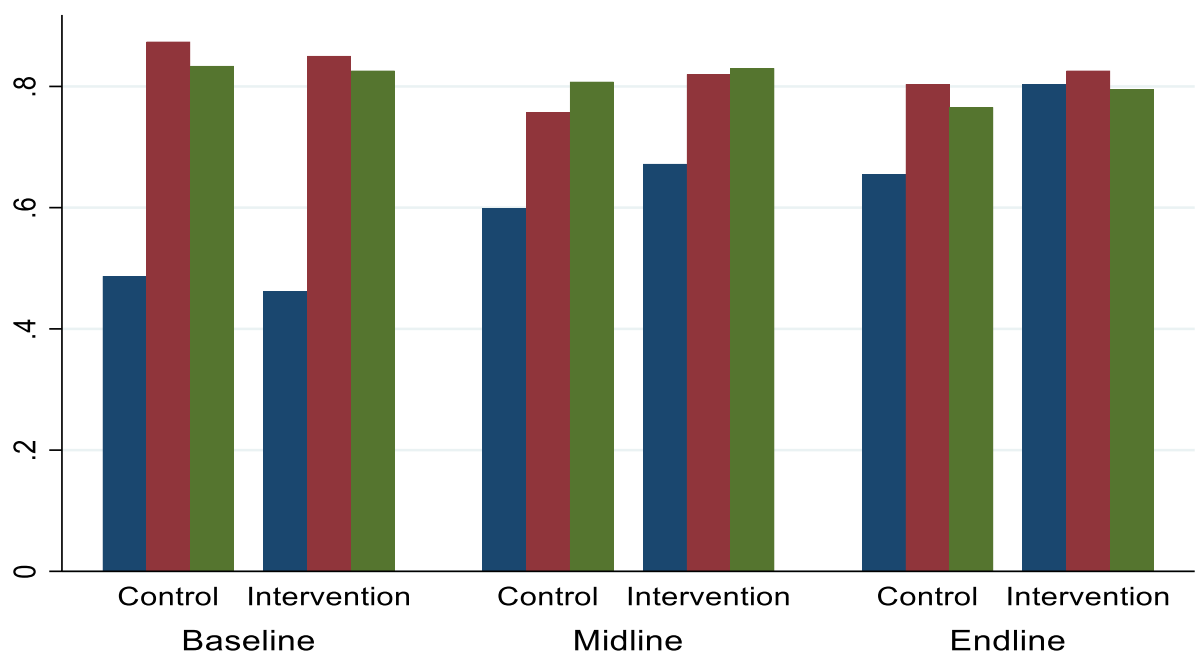

Clean_TLO Waste_to_Collector $\quad$ Source_Seregation

Fig. 6 Mean difference of the outcome variables in successive rounds of the survey by type of TLO. Source: Field survey 2017/2018

$$
\begin{aligned}
Y_{\text {htvw }}= & \beta_{w}+\beta_{1} \cdot \text { Intervention_TLO } O_{v w}+\beta_{2} \cdot m+\beta_{3} \cdot e \\
& +\beta_{4} \cdot \text { Intervention_TLO } O_{v w} \times m+\beta_{5} \cdot \text { Intervention_TLO } O_{v w} \\
& \times e+\beta_{6} X_{v w}+\varepsilon_{\text {htvw }}
\end{aligned}
$$

where the symbols are the same as in the case of Eq. (1) with the difference that Eq. (2) is estimated using all three rounds of survey data, where $m=$ midline dummy, $e=$ endline dummy, and $\beta_{4}$ and $\beta_{5}$ are the coefficients of the interaction terms that measure the impact of the intervention on the outcomes of interest at the midline and endline.

\section{Results and Discussion}

\subsection{Balancing Test}

Table 1 reports the characteristics of the sampled community and households from the baseline survey. On average, sixty-two percent of the respondents were female and they seemed better adept at handling household waste than their male counterpart (Nepal et al. $2022 \mathrm{a}, \mathrm{b})$. The average education of the respondents was around 9 years, with their average age being 43 years. Household characteristics were statistically balanced between the control and intervention TLOs. Two variables that were not balanced in the baseline between control and intervention groups were frequency of waste collection services in a given TLO and the number of meetings that the TLOs held during the previous year.

Table 1 also shows the outcome variables. They are: perceived cleanliness of TLO, waste given to collector, and waste segregated at home. The alternatives for those who did not give their waste to the collectors were burning or dumping in a nearby open space or drains. In the baseline, all outcome variables were balanced (Fig. 6). 
Table 2 Effect of intervention on MSW management (Eq. 1)

\begin{tabular}{|c|c|c|c|c|c|c|}
\hline \multirow[t]{2}{*}{ Variables } & \multicolumn{2}{|l|}{ Clean TLO } & \multicolumn{2}{|c|}{ Waste given to collector } & \multicolumn{2}{|c|}{ At-source segregation } \\
\hline & LPM (M1) & Logit (M2) & LPM (M3) & Logit (M4) & LPM (M5) & Logit (M6) \\
\hline Intervention TLOs & $\begin{array}{l}0.133 * * \\
(0.053)\end{array}$ & $\begin{array}{l}0.125 * * * \\
(0.048)\end{array}$ & $\begin{array}{l}0.080 * * \\
(0.030)\end{array}$ & $\begin{array}{l}0.076 * * * \\
(0.027)\end{array}$ & $\begin{array}{l}0.021 \\
(0.031)\end{array}$ & $\begin{array}{l}0.020 \\
(0.030)\end{array}$ \\
\hline Collection frequency & $\begin{array}{l}-0.030 \\
(0.062)\end{array}$ & $\begin{array}{l}-0.032 \\
(0.065)\end{array}$ & $\begin{array}{l}0.071 * * \\
(0.033)\end{array}$ & $\begin{array}{l}0.072 * * \\
(0.032)\end{array}$ & $\begin{array}{l}0.008 \\
(0.034)\end{array}$ & $\begin{array}{l}0.009 \\
(0.035)\end{array}$ \\
\hline TLO meetings & $\begin{array}{l}0.145^{*} \\
(0.081)\end{array}$ & $\begin{array}{l}0.129 \\
(0.080)\end{array}$ & $\begin{array}{l}-0.011 \\
(0.029)\end{array}$ & $\begin{array}{l}-0.016 \\
(0.029)\end{array}$ & $\begin{array}{l}0.024 \\
(0.038)\end{array}$ & $\begin{array}{l}0.018 \\
(0.030)\end{array}$ \\
\hline Spill-over effect & $\begin{array}{l}0.116 \\
(0.081)\end{array}$ & $\begin{array}{l}0.114 \\
(0.081)\end{array}$ & $\begin{array}{l}0.132 * * \\
(0.051)\end{array}$ & $\begin{array}{l}0.127 * * \\
(0.050)\end{array}$ & $\begin{array}{l}0.007 \\
(0.042)\end{array}$ & $\begin{array}{l}0.005 \\
(0.040)\end{array}$ \\
\hline Enumerator $\times$ Round & $\begin{array}{l}0.060 \\
(0.039)\end{array}$ & $\begin{array}{l}0.057 \\
(0.036)\end{array}$ & $\begin{array}{l}-0.011 \\
(0.010)\end{array}$ & $\begin{array}{l}-0.011 \\
(0.013)\end{array}$ & $\begin{array}{l}-0.008 \\
(0.011)\end{array}$ & $\begin{array}{l}-0.016 \\
(0.013)\end{array}$ \\
\hline Round 3 & $\begin{array}{l}-0.094 \\
(0.114)\end{array}$ & $\begin{array}{l}-0.084 \\
(0.107)\end{array}$ & $\begin{array}{l}0.056 \\
(0.036)\end{array}$ & $\begin{array}{l}0.050 \\
(0.032)\end{array}$ & $\begin{array}{l}-0.015 \\
(0.042)\end{array}$ & $\begin{array}{l}0.004 \\
(0.038)\end{array}$ \\
\hline Constant & $\begin{array}{l}0.096 \\
(0.256)\end{array}$ & & $\begin{array}{l}0.775 * * * \\
(0.069)\end{array}$ & & $\begin{array}{l}0.832 * * * \\
(0.089)\end{array}$ & \\
\hline Baseline mean of dep var & 0.487 & & 0.874 & & 0.834 & \\
\hline Observations & 1,986 & 1,986 & 1,986 & 1,986 & 1,986 & 1,986 \\
\hline R-squared & 0.262 & & 0.130 & & 0.147 & \\
\hline
\end{tabular}

Cluster-robust standard errors at the TLO level in parentheses; ***p< 0.01 , ** $p<0.05, * p<0.1$; ward fixed effects are used in all models. Coefficients from more parsimonious models have also been estimated and are available upon request. For logit models (M2, M4 and M6), marginal effects are reported

Figure 6 shows the difference in average values in successive rounds of the survey among the three outcomes, perceived cleanliness of the TLOs (Clean_TLO), waste given to collectors (Waste_to_Collector) and waste segregated at source (Source_Segregation). At the baseline, the sample means of these variables were comparable between the control and intervention TLOs. However, the reported cleanliness of the neighborhood is higher in the intervention TLOs in the midline and endline surveys. Although the average of the waste given to collectors is less (percentage of households) in successive rounds, the reduction is more in the control TLOs in comparison with the intervention TLOs. Waste segregation at source is similar in all three rounds except for some reduction in the endline control group.

\subsection{Spillover Effects}

Once the study project installed waste bins on the streets in the treatment TLOs, residents from some of the control TLOs also installed such bins in their streets with external support. In our sample, $12.5 \%$ of households from the control TLOs reported that they had street waste bins in round 2 of the survey. This number increased to $16.8 \%$ in round 3 . We accounted for this unexpected increase in street waste bins in the control TLOs in our regression estimates. Instead of dropping these observations, we estimated the spillover effect, defined as being 1 if 
and only if a household in a control TLO reported, in post-intervention surveys, that their TLO had waste bins on the streets (Table 2).

\subsection{Impact Estimation}

\subsubsection{Basic Specification}

Table 2 presents the results from the ordinary least squared (OLS) and logit estimates of Eq. 1, which show the impact of the intervention during either the midline or endline periods. Since the intervention TLOs are selected at random, the baseline information is mainly balanced except for two variables (see Table 1). The effect of the intervention on each outcome variable is estimated using two models. We also estimated a more parsimonious model for all three outcomes, which is not reported due to space constraints. The parsimonious model does not control for the two unbalanced variables (see Table 1): enumerator effects (enumerator IDs interacting with survey rounds as the same enumerators were not involved in all three rounds) and spillover effects (households in some of the control TLOs reporting the installation of street waste bins in their neighborhoods). In all the models, we used ward-level fixed effects to account for institutional and location-specific heterogeneity. The standard errors are clustered at TLO level.

The regression results in Table 2 show that the intervention (combined effect of the information campaign and street waste bin installation) has a positive impact on two of the three outcomes, clean TLO and waste given to the collector, with waste segregation being the exception. Overall, the intervention improved the perceived cleanliness of the TLOs by 13.3 percentage points (an increase of $27.3 \%$ ) and the tendency of households to give waste to collectors increased by 8 percentage points (an increase of $9.1 \%$ ) in comparison with the mean for the baseline control group. However, the intervention had no statistically significant impact on at-source waste segregation. It should be noted that the linear probability model (LPM) estimates are comparable (sign, significance and size) with logit estimates (marginal effects) in all three cases.

\subsubsection{Alternative Specification}

Since we have three rounds of panel data at the household level, we report an alternative specification (extended difference-in-difference (DID), see Eq. 2), where all three rounds of survey data (baseline, midline and endline) were used for examining the impact of the intervention on the three outcome variables (Table 3). We estimated two different models using LPM. Since we have three rounds of survey data, the extended DID estimation requires several interaction terms. The estimation of marginal effects, after logit estimates where interaction terms are/have been used, is not straightforward. Since the LPM coefficients and the marginal effects from logit models are comparable in sign, size and level of significance (Table 2), in Table 3, we report results from the LPM models. We estimate 
Table 3 Effect of intervention on MSW management (Eq. 2)

\begin{tabular}{|c|c|c|c|c|c|c|}
\hline \multirow[t]{2}{*}{ Variables } & \multicolumn{2}{|c|}{ Clean TLO } & \multicolumn{2}{|c|}{ Waste given to collector } & \multicolumn{2}{|c|}{ At-source segregation } \\
\hline & M1 & M2 & M3 & M4 & M5 & M6 \\
\hline Intervention TLOs & $\begin{array}{l}-0.027 \\
(0.027)\end{array}$ & $\begin{array}{l}-0.034 \\
(0.027)\end{array}$ & $\begin{array}{l}-0.025 \\
(0.023)\end{array}$ & $\begin{array}{l}-0.021 \\
(0.023)\end{array}$ & $\begin{array}{l}-0.012 \\
(0.023)\end{array}$ & $\begin{array}{l}-0.013 \\
(0.023)\end{array}$ \\
\hline Midline dummy & $\begin{array}{l}0.112 * * * \\
(0.027)\end{array}$ & $\begin{array}{l}0.085 * * \\
(0.034)\end{array}$ & $\begin{array}{l}-0.116^{* * * *} \\
(0.023)\end{array}$ & $\begin{array}{l}-0.076^{* * * *} \\
(0.029)\end{array}$ & $\begin{array}{l}-0.026 \\
(0.023)\end{array}$ & $\begin{array}{l}-0.052 * \\
(0.029)\end{array}$ \\
\hline Endline dummy & $\begin{array}{l}0.168 * * * \\
(0.027)\end{array}$ & $\begin{array}{l}0.129 * * * \\
(0.049)\end{array}$ & $\begin{array}{l}-0.070 * * * \\
(0.023)\end{array}$ & $\begin{array}{l}0.032 \\
(0.041)\end{array}$ & $\begin{array}{l}-0.068 * * * \\
(0.023)\end{array}$ & $\begin{array}{l}-0.117 * * * \\
(0.041)\end{array}$ \\
\hline $\begin{array}{l}\text { Midline dummy } \times \text { Inter- } \\
\text { vention TLOs }\end{array}$ & $\begin{array}{l}0.098 * * \\
(0.038)\end{array}$ & $\begin{array}{l}0.124 * * * \\
(0.039)\end{array}$ & $\begin{array}{l}0.086^{* * * *} \\
(0.032)\end{array}$ & $\begin{array}{l}0.114 * * * \\
(0.033)\end{array}$ & $\begin{array}{l}0.030 \\
(0.032)\end{array}$ & $\begin{array}{l}0.035 \\
(0.033)\end{array}$ \\
\hline $\begin{array}{l}\text { Endline dummy } \times \text { Inter- } \\
\text { vention TLOs }\end{array}$ & $\begin{array}{l}0.174 * * * \\
(0.038)\end{array}$ & $\begin{array}{l}0.211 * * * \\
(0.040)\end{array}$ & $\begin{array}{l}0.046 \\
(0.032)\end{array}$ & $\begin{array}{l}0.079 * * \\
(0.033)\end{array}$ & $\begin{array}{l}0.038 \\
(0.032)\end{array}$ & $\begin{array}{l}0.045 \\
(0.034)\end{array}$ \\
\hline Collection frequency & & $\begin{array}{l}0.026 \\
(0.022)\end{array}$ & & $\begin{array}{l}0.075^{* * *} \\
(0.018)\end{array}$ & & $\begin{array}{l}-0.007 \\
(0.018)\end{array}$ \\
\hline TLO meetings & & $\begin{array}{l}0.094 * * * \\
(0.024)\end{array}$ & & $\begin{array}{l}-0.010 \\
(0.020)\end{array}$ & & $\begin{array}{l}0.018 \\
(0.020)\end{array}$ \\
\hline Spillover effect & & $\begin{array}{l}0.102 * * * \\
(0.031)\end{array}$ & & $\begin{array}{l}0.110 * * * \\
(0.026)\end{array}$ & & $\begin{array}{l}0.020 \\
(0.027)\end{array}$ \\
\hline Enumerator $\times$ Round & & $\begin{array}{l}0.000 \\
(0.007)\end{array}$ & & $\begin{array}{l}-0.023 * * * \\
(0.006)\end{array}$ & & $\begin{array}{l}0.007 \\
(0.006)\end{array}$ \\
\hline Constant & $\begin{array}{l}0.488 * * * \\
(0.019)\end{array}$ & $\begin{array}{l}0.406^{* * *} \\
(0.035)\end{array}$ & $\begin{array}{l}0.874 * * * \\
(0.016)\end{array}$ & $\begin{array}{l}0.912 * * * \\
(0.029)\end{array}$ & $\begin{array}{l}0.836 * * * \\
(0.016)\end{array}$ & $\begin{array}{l}0.805^{* * * *} \\
(0.030)\end{array}$ \\
\hline $\begin{array}{r}\text { Baseline mean of dep } \\
\text { var in control TLOs }\end{array}$ & 0.487 & 0.487 & 0.874 & 0.874 & 0.834 & 0.834 \\
\hline Observations & 2,979 & 2,979 & 2,979 & 2,979 & 2,979 & 2,979 \\
\hline R-squared & 0.234 & 0.242 & 0.120 & 0.134 & 0.170 & 0.171 \\
\hline
\end{tabular}

Cluster robust standard errors at the TLO level in parentheses; ***p< $0.01, * * p<0.05, * p<0.1$. The F-statistic of the difference between effects at endline and midline on cleaner TLOs is $3.87(p=0.049)$ and on waste given to the collector is $1.16(p=0.280)$

two different models (parsimonious and full) for each outcome, where we use ward fixed effects. The standard errors are clustered at the TLO level. The results reported in Table 3 are, by and large, similar to those reported in Table 2, with the intervention showing no effect on waste segregation at source while it shows an improvement in perceived cleanliness of the TLO and waste given to collectors. 
The impact of the intervention on the cleanliness of the TLOs is positive and significant in both rounds with the perceived cleanliness improving by 12.4 percentage points at the midline (a $25 \%$ increase from the base) and by 21.1 percentage points (a $43 \%$ increase from the base) at the endline. The tendency of households to give waste to collectors increased by 11.4 percentage points at midline (a 13\% increase from the base) and by 7.9 percentage points (a $9 \%$ increase from the base) at the endline. On average, a 9-13\% increase in waste collection from households translates into an increase in waste collection by $1440-2080 \mathrm{~kg}$ per day from the households. ${ }^{8}$ There is a statistically significant increase between midline and endline in the effect of the intervention on perceived TLO cleanliness. However, the difference between the effects at midline and endline is not statistically significant with regard to waste given to the collector.

\subsection{Discussion}

In Nepal, among municipalities that collect solid waste, less than $50 \%$ of generated waste is collected. Uncollected waste is either dumped in a vacant lot in the neighbourhood or burnt by residents with consequent health, well-being and local infrastructure related costs. Our experimental evidence suggests that there are opportunities to improve waste management even in budget constrained municipalities.

Findings from our research indicate that low-cost soft interventions such as information to households on managing household waste better (information campaigns) and increased placement of street waste bins (low-cost physical infrastructure) can be effective in improving municipal solid waste management. Our analyses also suggest that the impact of installing street bins lasts longer than that of an information campaign. The effect of street bin installation on TLO cleanliness is higher in the endline survey relative to results from the midline survey, with the 8.7 percentage point increase in perceived street cleanliness between the two successive rounds of the survey being statistically significant. The time between bin installation and the start of the midline survey was 3 months and the endline survey was deployed 3 months later. Thus, the continued increase in perceived cleanliness may be because dayvisitors may have taken some time to transition from throwing waste on the street to putting it in street bins. Street bins are permanent fixtures and people see others using these bins. Thus, the continued presence of bins may reinforce, and increase 'good' street waste disposal behaviours as better disposal habits are formed. This result is generally consistent with increases in recycling practices when households are provided continuous and easy access to curb side recycling bins (Barr 2007).

Notably, waste disposal behaviour at the household level did not improve over time, i.e., there was no significant increase in waste disposal to collectors between midline and endline reports as a result of the information campaign. The information campaign was a one-time effort where households received basic information on managing household waste. Behaviour change, however, takes time to become habituated and may need to be fortified to persist over time (Bhardwaj et al. 2021). Thus, to sustain the effects of an information campaign, a periodic reminder to households may be useful. While we cannot be fully certain of the reasons,

\footnotetext{
${ }^{8}$ CBS (2021) indicates that the average waste collected from households in 2019 was close to $16,000 \mathrm{~kg}$ per metropolitan city in Nepal. Therefore, $13 \%$ improvement in waste collection means collecting an additional $2080 \mathrm{~kg}$ of waste per day.
} 
the absence of reinforcement or reminders may be why the effects of the information campaign did not persist over time.

Our third set of results relate to the challenges in increasing at-source segregation. Our findings show that increasing awareness and providing information was insufficient in changing household practices related to at-source segregation. The likely explanation for this is that private contractors in Bharatpur did not change their waste collection practices. It is to be noted that changing private contractors' behaviour was not a part of the intervention since this issue was not identified by the stakeholders while planning for this study. Because waste segregated by households was not collected, transported and managed separately, households probably did not see any point in segregating waste at source.

The spill-over effect (the effect of waste bins installed in the control TLOs after the intervention) on 'clean TLO' and 'waste given to collector' is 11-13 percentage points in both cases and comparable with the effect in the intervention TLOs.

\section{Conclusions and Policy Implications}

Municipal solid waste management is a key challenge faced by many cities in South Asia (Haque et al. 2019). Improperly managed solid waste increases flooding and waterlogging risks and reduces the returns on costly urban infrastructure investments such as drainages networks (Pervin et al. 2020). Both climate change, which increases the likelihood of extreme weather events, and continued urban population growth underscore the importance of improving solid waste management to ensure the wellbeing and financial viability of cities and their residents. Our study findings, applicable to other cities in Nepal and across Asia, suggest that behavioural and low-cost interventions offer cost-effective complementary strategies to more costly investments in municipal infrastructure.

Using a cluster randomized control trial experiment in a fast-growing metropolitan city in Nepal, we show that low-cost street bin installation and information dissemination can have a positive impact on household waste management and perceptions of street cleanliness. The average cost of installing a street waste bin is approximately USD 5 per bin and information provision costs USD 3 per household. These costs include all components such as bin purchases and installation, mobilizing trainers, and coordination of intervention activities. When compared with baseline averages, these low-cost interventions in treatment sites contributed to an approximately $34 \%$ increase in the perceived cleanliness of neighbourhoods and a $13 \%$ increase in households' tendency to give waste to collectors rather than dumping waste in open spaces/drains or burning. The positive results associated with street bin installation are particularly policy relevant as they persist over time. We installed 1500 bins at a cost of USD 5 per bin in our intervention areas, an amount that most municipalities can likely afford.

Awareness and information provision do not have an effect on at-source segregation of household waste, likely because of segregated waste being re-mixed by contractors responsible for collection. This waste management issue must be addressed on a priority basis as at-source segregation is a first step in improving recycling and composting in cities like Bharatpur, where around $70 \%$ of the household waste is organic (Rai et al. 2019). Recycling would increase substantially if waste is segregated, potentially generating a new revenue stream for the municipality while reducing plastic pollution (Bharadwaj, Rai and Nepal 2020). Other benefits include increases in municipal tax 
revenues because home values improve in cleaner neighbourhoods (Nepal et al. 2020). Moreover, better management of municipal solid waste lowers the risk of waterlogging during the monsoon season helping to make the city more liveable for its residents and cutting down on municipal costs of clean up and restoration (Pervin et al. 2020).

Based on the results of our study, city officials in Bharatpur recently developed a management proposal to separate collection of biodegradable and non-degradable waste, contingent on households and businesses segregating at source. However, the new plan faces another major hurdle in the form of limited sanitary landfill sites for managing non-degradable waste and lack of composting facilities for organic waste. These pre-conditions must be addressed to benefit from at-source waste segregation, reinforcing the need for system-wide strategies that include infrastructural investments and behavioural incentives for successful municipal waste management.

\section{Appendix: A sample of the Posters and Information Used in the Information Workshops}

See Figs. 7 and 8.

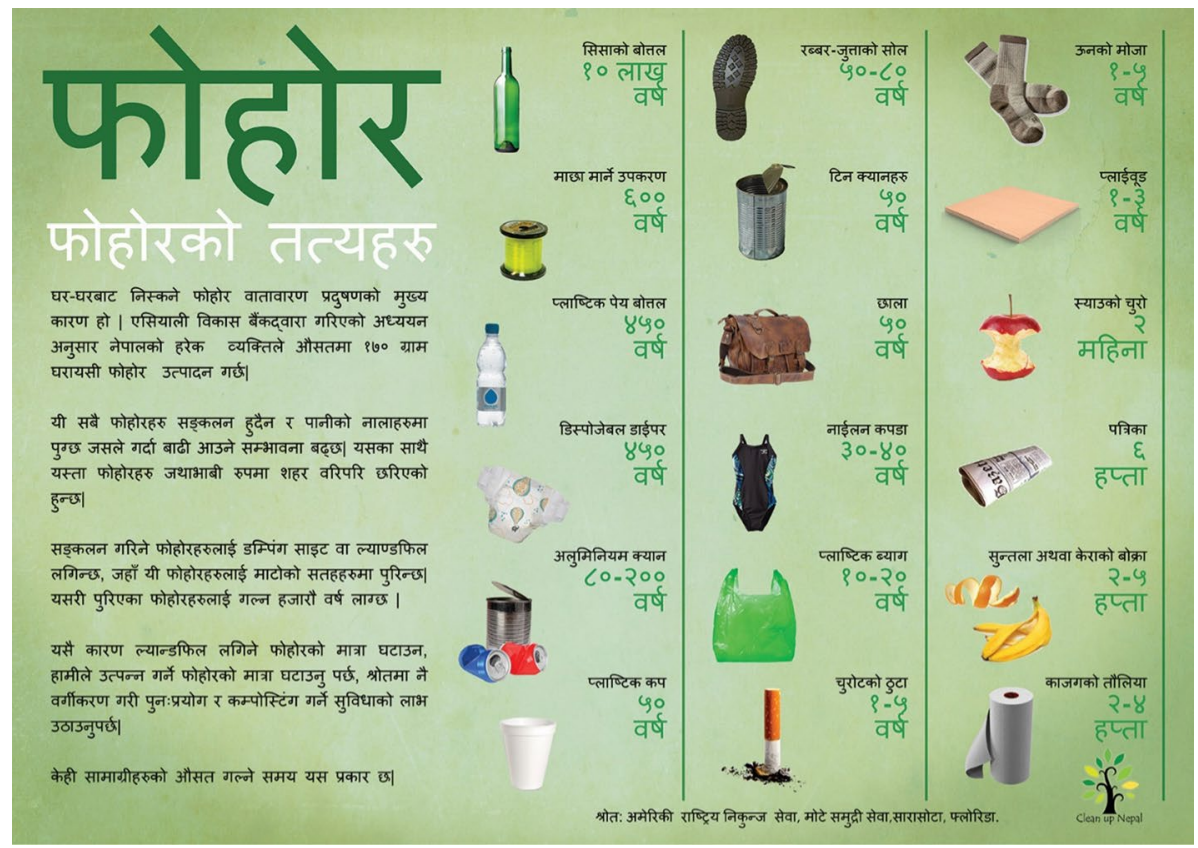

Fig. 7 Components of household waste and their lifespan 


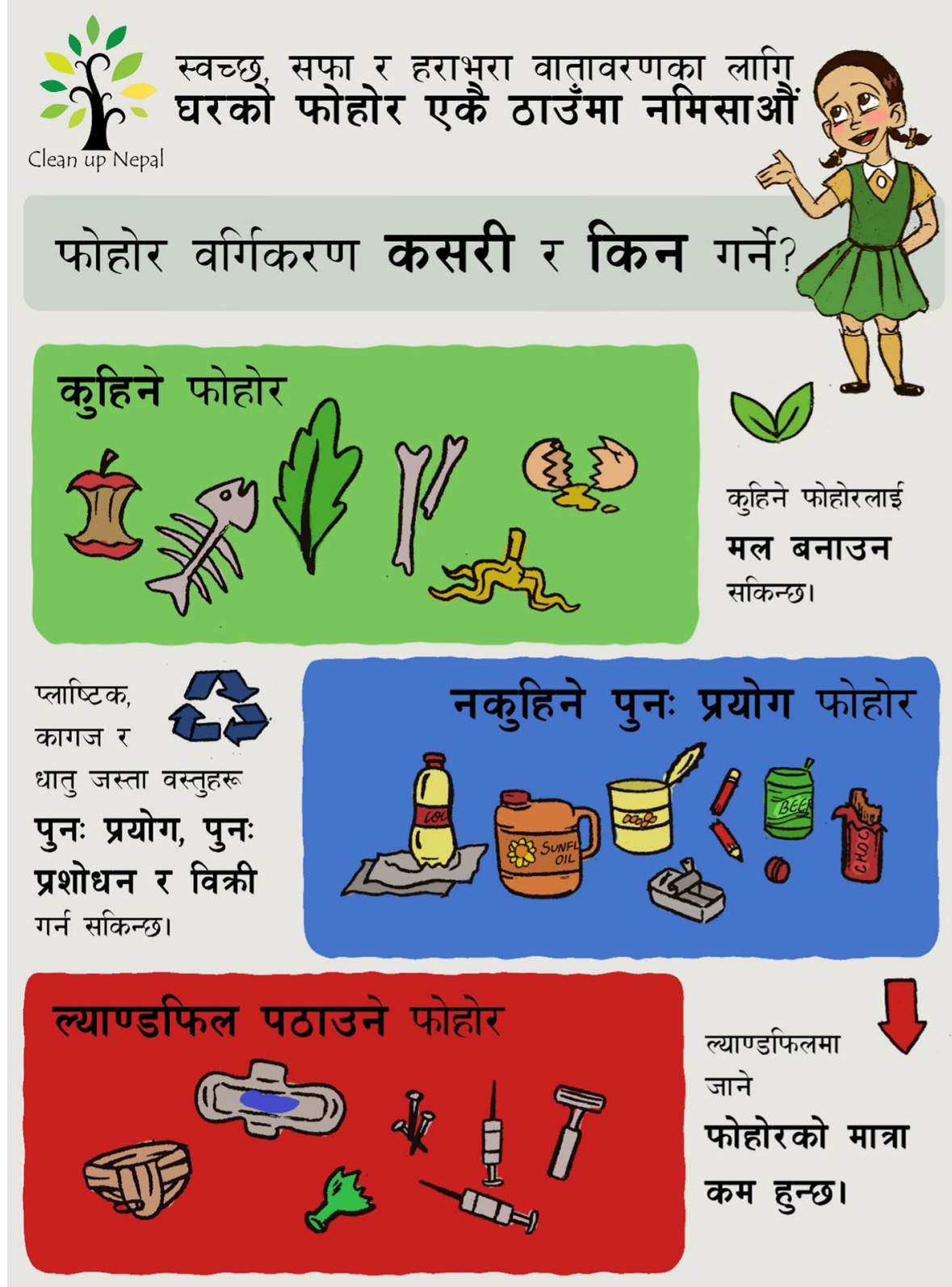

क्लिन अप नेपाल, टंगाल, काठमाडौं, फोन ०१ ४४२२६३३, इमेल info@cleanupnepal.org.np

Fig. 8 Classification of waste into decomposable, reusable and refuse for landfill 
Acknowledgements The authors would like to acknowledge the International Development Research Center (IDRC), Ottawa, Canada, for providing financial support (Grant \#08283-001) under the Cities and Climate Change research (2017-2020) for this study. The International Center for Integrated Mountain Development (ICIMOD), to which the first author is affiliated, acknowledges with gratitude the support of the Governments of Afghanistan, Australia, Austria, Bangladesh, Bhutan, China, India, Myanmar, Nepal, Norway, Pakistan, Sweden, and Switzerland. The research team received support from Birat Ghimire and the Bharatpur Metropolitan City for the fieldwork and Clean Up Nepal helped installing the bins and organizing the sensitization workshops. However, the views as well as the analysis and interpretations of the results presented in this research are those of the authors and should not be attributed to their affiliated organizations, their supporters, or the funding agency.

Open Access This article is licensed under a Creative Commons Attribution 4.0 International License, which permits use, sharing, adaptation, distribution and reproduction in any medium or format, as long as you give appropriate credit to the original author(s) and the source, provide a link to the Creative Commons licence, and indicate if changes were made. The images or other third party material in this article are included in the article's Creative Commons licence, unless indicated otherwise in a credit line to the material. If material is not included in the article's Creative Commons licence and your intended use is not permitted by statutory regulation or exceeds the permitted use, you will need to obtain permission directly from the copyright holder. To view a copy of this licence, visit http://creativecommons.org/licenses/by/4.0/.

\section{References}

Abbasi A, Araban M, Heidar Z, Alidosti M, Zamani-Alavijeh F (2020) Comparing the impact of educational messages based on an extended parallel process model on solid waste separation behaviors in female students: a four-group randomized trial. Waste Manage 117:1-8

Alawadhi S, Aldama-Nalda A, Chourabi H, Gil-Garci J R, Leung S, Mellouli S et al (2012) Building understanding of smart city initiatives. In: International conference on electronic government, Springer, pp 40-53.

Almazán-Casali S, Alfaro JF, Sikra S (2019) Exploring household willingness to participate in solid waste collection services in Liberia. Habitat Int 84:57-64

Asian Development Bank (2013) Solid Waste Management in Nepal: current Status and Policy Recommendations. Asian Development Bank (ADB), Manila

Barr S, Gilg AW, Ford NJ (2001) A conceptual framework for understanding and analysing attitudes towards household-waste management. Environ Plan A 33(11):2025-2048

Barr S (2007) Factors influencing environmental attitudes and behaviors: a UK case study of household waste management. Environ Behav 39(4):435-473

Bharadwaj B, Baland JM, Nepal M (2020a) What makes a ban on plastic bags effective? The case of Nepal. Environ Dev Econ 25(2):95-114

Bharadwaj B, Rai R K, Nepal M (2020b) Sustainable financing for municipal solid waste management in Nepal. Plos One 15(8):e0231933

Bharadwaj B, Subedi MN, Chalise BK (2021) Where is my reusable bag? Retailers' bag use before and after the plastic bag ban in Dharan Municipality of Nepal. Waste Manage 120:494-502

CBS (2021). Waste management baseline survey of Nepal 2020. The Central Bureau of Statistics, Kathamndu, Nepal.

Cohen B (2006) Urbanization in developing countries: current trends, future projections, and key challenges for sustainability. Technol Soc 28(1-2):63-80

Cotterill S, John P, Liu H, Nomura H (2009) Mobilizing citizen effort to enhance environmental outcomes: a randomized controlled trial of a door-to-door recycling campaign. J Environ Manage 91(2):403-410

Desa A, Kadir NBA, Yusooff F (2011) A study on the knowledge, attitudes, awareness status and behaviour concerning solid waste management. Procedia Soc Behav Sci 18:643-648

Esmaeilian B, Wang B, Lewis K, Duarte F, Ratti C, Behdad S (2018) The future of waste management in smart and sustainable cities: a review and concept paper. Waste Manage 81:177-195

Guerrero LA, Maas G, Hogland W (2013) Solid waste management challenges for cities in developing countries. Waste Manage 33(1):220-232

GoN (2018). The Government Operation Act 2018. The Government of Nepal, Kathamndu.

Haque AKE, Lohano HD, Mukhopadhyay P, Nepal M, Shafeeqa F, Vidanage SP (2019) NDC pledges of South Asia: are the stakeholders onboard? Clim Change 155(2):237-244 
Hasan SE (2004) Public awareness is key to successful waste management. J Environ Sci Health Part A 39(2):483-492

Henry RK, Yongsheng Z, Jun D (2006) Municipal solid waste management challenges in developing countries - Kenyan case study. Waste Manage 26(1):92-100

Hosono T, Aoyagi K (2018) Effectiveness of interventions to induce waste segregation by households: evidence from a randomized controlled trial in Mozambique. J Mater Cycles Waste Manage 20(2):1143-1153

Huang YT, Pan TC, Kao JJ (2011) Performance assessment for municipal solid waste collection in Taiwan. J Environ Manage 92(4):1277-1283

Hoornweg D, Bhada-Tata P (2012) What a waste: a global review of solid waste management. The World Bank Urban Development Series, Washington DC

Joseph K (2006) Stakeholder participation for sustainable waste management. Habitat Int 30(4):863-871

Kalyanasundaram M, Sabde Y, Annerstedt KS, Singh S, Sahoo KC, Parashar V, Diwan V (2021) Effects of improved information and volunteer support on segregation of solid waste at the household level in urban settings in Madhya Pradesh, India (I-MISS): protocol of a cluster randomized controlled trial. BMC Public Health 21(1):1-11

Khandker SR, Koolwal GB, Samad HA (2009) Handbook on impact evaluation: quantitative methods and practices. World Bank, Washington, DC

Levitt SD, List JA (2011) Was there really a Hawthorne effect at the Hawthorne plant? An analysis of the original illumination experiments. Am Econ J Appl Econ 3(1):224-238

Medvedev A, Fedchenkov P, Zaslavsky A, Anagnostopoulos T, Khoruzhnikov S (2015) Waste management as an IoT-enabled service in smart cities. In: Internet of things, smart spaces, and next generation networks and systems, Springer, pp 104-115.

Nam T, Pardo TA (2011) Smart city as urban innovation: focusing on management, policy, and context. In: Proceedings of the 5th international conference on theory and practice of electronic governance (pp. 185-194).

Nepal M, Rai RK, Khadayat MS, Somanathan E (2020) Value of cleaner neighborhoods: application of hedonic price model in low income context. World Development 131:104965

Nepal M, Bharadwaj B, Karki Nepal A, Khadayat MK, Pervin IA, Rai RK, Somanathan E (2022a) Marking urban waste managing and drainage sustainable in Nepal. In: Hauqe AKE, Mukhopadhyaya P, Nepal M, Shammin MR (eds) Climate change and community reslience: insights from South Asia. Springer Nature, Singapore, pp 325-338

Nepal M, Cauchy M, Karki Nepal A, Gurung GC (2022b) Household waste management and gender in Nepal. In: Acharyya A (ed) Environmental economics in developing countries: issues and challenges (forthcoming). Routledge, India

Nomura H, John PC, Cotterill S (2011) The use of feedback to enhance environmental outcomes: a randomised controlled trial of a food waste scheme. Local Environ 16(7):637-653

Pervin IA, Rahman SM, Nepal M, Haque AKE, Karim H, Dhakal G (2020) Adapting to urban flooding: a case of two cities in South Asia. Water Policy 22(S1):162-188

Priti and Mandal (2019) Review on evolution of municipal solid waste management in India: practices, challenges and policy implications. J Mater Cycles Waste Manage 21(6):1263-1279

Rai RK, Nepal M, Khadayat MS, Bharadwaj B (2019) Improving municipal solid waste collection services in developing countries: a case of bharatpur metropolitan city Nepal. Sustainability 11(11):3010

SWMRMC (2004) Solid Waste managmenet in nepalese municipalities: solid waste management in bharatpur municipality. Kathmadu.

Tawhid K G (2004) Causes and effects of water logging in Dhaka City, Bangladesh. TRITA-LWR master thesis, Department of Land and Water Resource Engineering, Royal Institute of Technology, Stockholm

Tucker P, Speirs D (2003) Attitudes and behavioural change in household waste management behaviours. J Environ Planning Manage 46(2):289-307

UN-Habitat. (2004) The challenge of slums: global report on human settlements 2003. Manag Environ Qual Int J 15(3):337-338

Visvizi A, Lytras MD, Damiani E, Mathkour H (2018) Policy making for smart cities: innovation and social inclusive economic growth for sustainability. J Sci Technol Policy Manag 9(2):126-133

Publisher's Note Springer Nature remains neutral with regard to jurisdictional claims in published maps and institutional affiliations. 


\section{Authors and Affiliations}

Mani Nepal ${ }^{1}$ (D) . Apsara Karki Nepal ${ }^{2} \cdot$ Madan S. Khadayat $^{3} \cdot$ Rajesh K. Rai $^{4}$. Priya Shyamsundar $^{5}$ E. Somanathan ${ }^{6}$

Apsara Karki Nepal

apsunkarki@gmail.com

Madan S. Khadayat

madankdyt@yahoo.com

Rajesh K. Rai

rjerung@gmail.com

Priya Shyamsundar

priya.shyamsundar@tnc.org

E. Somanathan

som@isid.ac.in

1 South Asian Network for Development and Environmental Economics (SANDEE), International Center for Integrated Mountain Development (ICIMOD), Kathmandu, Nepal

2 International Center for Integrated Mountain Development (ICIMOD), Kathmandu, Nepal

3 Freelance Researcher, Kathmandu, Nepal

4 Institute of Forestry, Tribhuvan University, Kathmandu, Nepal

5 The Nature Conservancy, Arlington, VA, USA

6 Indian Statistical Institute, New Delhi, India 